\title{
An Amperometric Biosensor Based on Fumarate Reductase for Enzymatic Properties and Electrical Behavior
}

\author{
Yemin Yu, Yonghong Hu, Tao Li, Wenge Yang, Yuhao zhang, and Renlun Deng
}

\begin{abstract}
In this paper, the production of fumarate reductase was studied. Through ultrasonic separation, gel chromatography and $65 \%$ ammonium sulfate fractionation, the fumarate reductase specific activity reached to $106 \mathrm{U} / \mathrm{mg}$, the purification ratio was 12.8 times and the recovery was $24 \%$. Fumarate reductase was fixed on electrode, which was modified polyethyleneimine reductive graphene composites, through covalent bonding and electrostatic adsorption. The electrode was used to replace coenzyme NADH in the cell inside metabolism, constructing a fumarate reductase catalytic system based on electrical driving.

The results showed that fumaric acid reductase immobilized on the electrode not only maintained a certain biological activity, but also could catalyze the metabolism of fumaric acid. Thus, the electrical catalysis of fumarate reductase/polyethyleneimine reductive graphene composites/glassy carbon electrode and the substrate of fumaric acid based on fumarate reductase were studied, providing a scientific theoretical basis for the production of succinic acid in vitro.
\end{abstract}

Index Terms-Fumarate reductase, fumaric acid, succinic acid, electronical catalytic behavior.

\section{INTRODUCTION}

Bio-based chemicals are series of products that are derived from renewable biomass and catalyzed by biological cells or enzymatic proteins. Succinic acid is ranked by the US Department of Energy's 12 kinds of biological-based bulk chemicals, the large-scale production process is one hot focus at home and abroad, compared with the traditional chemical synthesis process, bio-high technology has the advantage of small pollution.

Succinic acid $\left(\mathrm{C}_{4} \mathrm{H}_{6} \mathrm{O}_{4}\right.$, CAS number 110-15-6, molecular weight 118.09, Fig. 1), is an important chemical raw material and main "C4 platform compound" that can be converted to 1,4-butanediol, tetrahydrofuran, 6,4-butyrolactone and other four-carbon chemicals. It has a wide range of use in medicine, food and surfactant industry [1]. Succinic acid is an important member of the tricarboxylic acid cycle, and the metabolic regulation of the living body plays a pivotal role. As a surfactant, cleaning additive, ion chelating agent, acidifying

Manuscript received September 30, 2017; revised November 30, 2017.This work was supported in part by the state key development program of China (2016YED0201002).

The authors are with College of Biotechnology and Pharmaceutical Engineering, State Key Laboratory of Materials-Oriented Chemical Engineering, Nanjing Tech University, Nanjing 211816, China (e-mail:1253753161@qq.com, yonghonghu11@126.com). agent and antidote, etc., in food, medical care and health care products, Electroplating and other industries occupy a very important position. At present, many of the chemical products are based on benzene as raw materials. As one petrochemical products, benzene is not renewable. Hence, from the consideration of long-term, it is very meaningful to find one kind of right renewable raw materials to replace benzene. With the development of catalytic processes, succinic acid can also be converted to more chemical products, such as succinic acid hydrogenation of butanediol can be carboxylated adipic acid. In the food field, succinic acid is an ideal sour agent. Succinic acid sodium salt can improve the quality of soy sauce, soy sauce, liquid seasoning and refining products. In the harmaceutical industry, succinic acid is one active ingredients of traditional Chinese medicine amber, been involved in energy metabolism and affecting excitability. One interesting thing is that succinic acid can also be used as a plant growing agent.

Fumarate reductase is an enzyme that changes the fumaric acid to succinic acid by achieving $\mathrm{H}$ from $\mathrm{NADH}$ and is important in microbial metabolismas a part of anaerobic respiration (Fig. 2, 3).The enzyme is widely found in gram-negative bacteria, facultative anaerobic gram-positive bacteria, as well as some green algae, protozoa, parasitic worms and low ocean eukaryotes [2], [3]. In other words, fumarate reductase couples the reduction of fumarate to succinate to the oxidation of quinol toquinone, in a reaction opposite to that catalysed by the related complex II of the respiratory chain (succinate dehydrogenase). Fumarate reductase is a staple enzyme in the tricarboxylic acid cycle. The reverse enzyme is a succinate dehydrogenase. As a key enzyme in many biological anaerobic respiration, it plays very important role. It not only can catalyze the reduction of fumaric acid to succinic acid but also can be a potential shoe gene for the treatment of many diseases because both the mammal and the human do not contain fumarate reductase in while the microbes causing various diseases contain. The fumarate reductase, which has been studied, can be divided into two types of membrane-bound and soluble. Most of the fumarate reductase belongs to the membrane-bound type, with three kinds of subunits, one catalytic subunit, one iron family of subunits and anchoring subunits that bind the catalytic subunit and iron cluster protein subunits to the membrane. The catalytic subunit contains active sites, while the iron cluster protein subunits pass electrons to the catalytic subunit by paving the subunits. This type of fumarate reductase mainly 
in the anaerobic conditions and maintaining oxygen balance will be functional to produce succinic acid from fumaric acid.

However, the traditional chemical way of synthesizing succinic acid is limited due to cost and environmental pollution, making the limitation of wide range of applications when succinic acid is used as the basic chemical raw materials. Fermentation producing succinic acid has many advantages. First, it is reported that using a new microbial fermentation process and a new recovery process for electrodialysis and liquid-liquid extraction, whose cost is much lower than that of the traditional chemical production method. Thus, the traditional chemical way of synthesizing succinic acid will give way to fermentation. Secondly, because of the environment-friendly feature, the cost reduction is beneficial to the wide use range of applications of succinic acid as organic synthesis intermediates. Third, the fermentation production of succinic acid is based on renewable sources, such as glucose and carbon dioxide as the main raw material, the new process of producing benzene and other petrochemical products market prospects is social and environmental. This way not only gets out of the dependence on petrochemical raw materials, but also opens up a new utilization way of greenhouse gas carbon dioxide [4], [5]

At present, the research on fumarate reductase is mainly focused on the application of the enzyme, articles in the world talking about purification methods and the nature of the enzymology is not a lot. In the enzymatic fermentation, fumarate reductase plays a key role in the direct conversion of converting fumaric acid to succinic acid. Fumarate reductase as a key enzyme in the production of succinic acid, its research has become increasingly important. What's more, the enzymatic properties of fumarate reductase vary greatly depend on different strains. It is necessary to study the basic characteristics and enzymatic properties of fumarate reductase by using intracellular fumarate reductase to transform fumaric acid into succinic acid.In this study, the preliminary purification of fumarate reductase produced by Brevibacterium ammoniagenes was studied, which provided atheoretical guidance for industrial application of fumarate reductase.

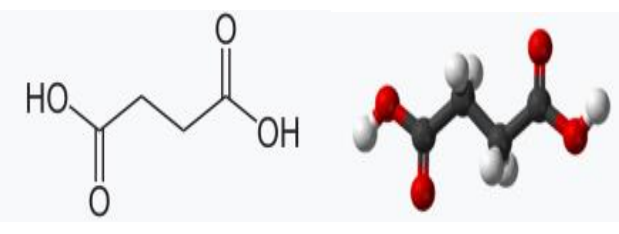

Fig. 1. Structure of succinic acid.

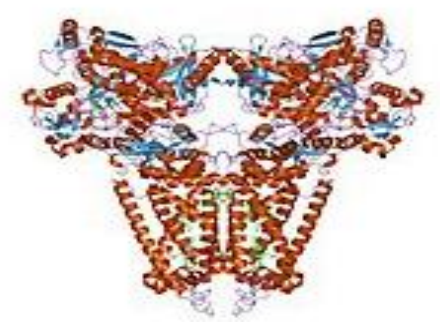

Fig. 2. Fumarate + fumarate reductase $=>$ succinic acid.

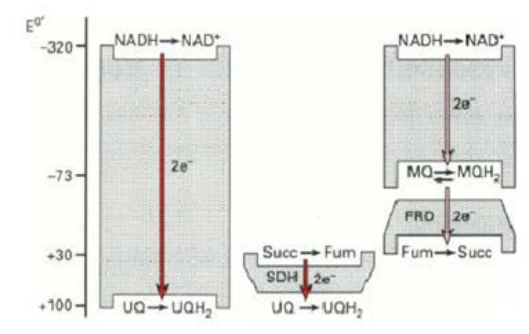

Fig. 3. Fumarate reductase catalyzes fumaric acid to succinic acid.

\section{EXPERIMENTAl Materials And Methods}

\section{A. Experimental Strains}

Brevibacterium ammoniagenes MA-2, deposited in China Strain Collection Center.

\section{B. Medium}

a) Activation medium $(\mathrm{g} / \mathrm{L})$ : peptone 10 , beef extract 5 , NaCl 5, agar 20, pH 7.0.

b) Seed medium (g/L): glucose 20, corn steep liquor 15 , urea 2, $\mathrm{KH}_{2} \mathrm{PO}_{4} 2, \mathrm{MgSO}_{4} \cdot 7 \mathrm{H}_{2} \mathrm{O}$ 0.5, $\mathrm{pH}$ 7.0.

c) Fermentation medium (g/L): glucose 20, corn steep liquor 30, urea 2, fumaric acid 20, $\mathrm{KH}_{2} \mathrm{PO}_{4} 2, \mathrm{MgSO}_{4} \cdot 7 \mathrm{H}_{2} \mathrm{O}$ 0.5 , pH 7.0 .

\section{Species Culture Methods}

a) Activate strain: from the glycerol preservation tube in the refrigerator, Pick out a ring bacteria. Put $50 \mathrm{~mL}$ activation medium in $250 \mathrm{~mL}$ flask. Under the conditions of $32^{\circ} \mathrm{C}, 180 \mathrm{r}$ / min, shake flask for 24 hours.

b) Cultivate strain: Absorb $1 \mathrm{~mL}$ of bacterial fluid from the activation medium, to $250 \mathrm{~mL}$ Erlenmeyer flask with $50 \mathrm{~mL}$ seed medium. Under the conditions of $32{ }^{\circ} \mathrm{C}, 180 \mathrm{r} / \mathrm{min}$, shake flask for 24 hours.

c) Shake flask culture: Absorb $10 \%$ bulk of bacterial fluid from the seed medium, to $250 \mathrm{~mL}$ Erlenmeyer flask with 50 $\mathrm{mL}$ fermentation. Under the conditions of $32{ }^{\circ} \mathrm{C}, 180 \mathrm{r} / \mathrm{min}$, shake flask for 48 hours.

\section{Optimization of Fermentation Medium for Fermentation}

Determination of fumarate reductase activity: fumarate reductase catalyzes substrate fumaric acid to succinic acid. Succinic acid at $210 \mathrm{~nm}$ has a special absorption peak. According to the characteristics of the reaction to determine the concentration of succinic acid to measure fumarate reductase activity.

Specific methods: collect the Brevibacterium ammoniagenes MA-2 cells after the end of the fermentation, washed with stroke-physiological saline solution. Then use stroke-physiological saline solution to make bacteria suspension which per $\mathrm{ml}$ contain $0.1 \mathrm{~g}$ wet for the determination of fumarate reductase activity. $0.5 \mathrm{ml}$ was added to $2.0 \mathrm{~mL} 1 \mathrm{M}$ fumarate $(\mathrm{pH} 7.0$ ) solution containing $0.4 \%$ of cholic acid, reacting at $37^{\circ} \mathrm{C}$ for 1 hour. The reaction mixture was boiled for $5 \mathrm{~min}$ and texted at $210 \mathrm{~nm}$ using an ultraviolet spectrophotometer. Enzyme activity units (U) are defined as: 
in appropriate catalytic conditions, the amount of enzyme catalyzes fumaric acid to produce $1 \mu \mathrm{mol}$ succinic acid per hour.

We will study the effect of three medium components.

The effect of nitrogen source on the enzyme production: The contents of organic nitrogen (peptone, yeast extract, beef extract, corn steep liquor) and inorganic nitrogen (diammonium citrate, urea, $\left(\mathrm{NH}_{4}\right)_{2} \mathrm{SO}_{4}$ ) were selected as the initial medium in the process of optimization of nitrogen source. The effect of each nitrogen source medium based on fumarate reductase activity was determined by shaking flask culture, and the appropriate nitrogen source was selected.

The effect of carbon source on the enzyme production: After select the optimal nitrogen source, the optimum carbon source fermentation conditions were as follows: glucose, sucrose, maltose, inositol, lactose and soluble starch. The effect of each carbon source medium o based on fumarate reductase activity was determined after shaking flask culture. Thus, select the appropriate carbon source.

The effect of inorganic salt ions on enzyme production: Based on the optimal carbon source and nitrogen source, the fermentation medium was prepared by different inorganic salt ions $\mathrm{MgSO}_{4} \cdot 7 \mathrm{H}_{2} \mathrm{O}, \mathrm{KH}_{2} \mathrm{PO}_{4}, \mathrm{NaCl}, \mathrm{ZnSO}_{4}, \mathrm{CuSO}_{4}$ and $\mathrm{CaCO}_{3}$. After shaking flask culture, each inorganic salt medium was tested for fumarate reductase activity. Thus, select the appropriate concentration of inorganic salt ions.

Then, using the Plackett-Burman experiment, the factors influencing the activity of fumarate reductase were screened out from a number of independent single factors. Each variable had high (+) and low (-) 2 levels. The use the Design Expert software to analyze the experimental results, examine the significance of each factor, screening out the most important factors. Based on the initial shake flask fermentation test, 9 single factors related to fermentation were tested in the previous experiment, namely glucose, sucrose, soluble starch, corn steep liquor, ammonium sulfate, diammonium citrate, $\mathrm{KH}_{2} \mathrm{PO}_{4}, \mathrm{MgSO}_{4} 7 \mathrm{H}_{2} \mathrm{O}, \mathrm{CaCO}_{3}$, and the evaluation index was the activity of fumarate reductase in fermentation broth.

\section{E. Acquisition of Fumarate Reductase}

a) Obtaining strain: The fermentation broth containing the cells was filtered and washed with $0.05 \mathrm{~mol} / \mathrm{L} \mathrm{K}_{3} \mathrm{PO}_{4}$ buffer for 3 times, and centrifuged at $2000 \mathrm{r} / \mathrm{min}$ for 20 minutes to collect precipitation.

b) Cell fragmentation: Add $\mathrm{K}_{3} \mathrm{PO}_{4}$ buffer to wash the precipitation. Centrifugate to get precipitation. Repeat for two times. The lysate was added to the centrifuge tube at a rate of $50 \mathrm{~mL}$ fermentation liquid adding $2 \mathrm{~mL}$ lysate. Small magnetics were added under the conditions of $4^{\circ} \mathrm{C}, 1500 \mathrm{rpm}$ for 3 hours. Then put into the $-20^{\circ} \mathrm{C}$ refrigerator frozen. At last, in the ultrasonic cleaning machine, liquid was treated by ice bath and ultrasound for 30 minutes.

c) Ammonium sulfate precipitation [6], [7]: The solution obtained above was centrifuged to obtain a supernatant. Protamine sulfate solution, whose $\mathrm{pH}$ is 7.0 , at a bulk of $20 \%$ of the supernatant, was added to the supernatant. The mixed solution was centrifuged after 1 hour. The supernatant was graded by adding ammonium sulfate precipitation. A total of 7 ammonium sulfate gradients experiment is $0 \%, 15 \%, 25 \%$, $35 \%, 45 \%, 55 \%$ and $65 \%$. $50 \mathrm{~mL}$ of the 8 same volume of supernatant was added solid ammonium sulphate to the above different saturation, stirring for 40 minutes and then being stored for 24 hours. Through being centrifugated at 12000 $\mathrm{r} / \mathrm{min}$ for 30 minutes, the supernatant was discarded and the fumarate reductase precipitate sediment was obtained.

d) Dialysis overnight. The precipitate obtained above was suspended with the phosphate buffer $(\mathrm{pH}=7.5)$. Using dialysis bag, dialysis the mixture for $48 \mathrm{~h}$ (molecular weight $=30 \mathrm{kD}$ ). In this process, the dialysate was replaced every 6 hours. At last, the fumarate reductase was obtained and stored at $4^{\circ} \mathrm{C}$ for use.

\section{F. Electrical Detection Of Fumaric Acid Reductase Method}

1) Preparation of polyethyleneimine reductive graphene composites (PEI-RGO) [8]-[10]

Firstly, $1.5 \mathrm{~mL}$ (concentration at $2 \mathrm{mg} / \mathrm{mL}$ ) was diluted to $25.5 \mathrm{~mL}$. Constantly stirring, reduced graphene was added to $4.5 \mathrm{~mL}$ (0.2 wt\%) of polyethyleneimine solution. After 10 minutes, make a refluxed reaction at $135^{\circ} \mathrm{C}$ for 3.5 hours. Secondly, after the reaction, the product was naturally cooled and then centrifuged for 10 minutes at $13000 \mathrm{rpm} / \mathrm{min}$. Thirdly, the product was washed by water for several times. Finally, the product was put in $2 \mathrm{~mL}$ water with ultrasonic shake and stored in a dry and cool place for use.

\section{2) Preparation of glassy carbon electrode (GCE)}

The glassy carbon electrode (GCE) with a diameter of 3mm was polished successively on the suede with $1.0 \mu \mathrm{m}$ and $0 . \mu \mathrm{m}$ $\mathrm{Al}_{2} \mathrm{O}_{3}$ powder to make the surface of the GCE smooth as a mirror. The surface was washed with distilled water and then treated by ultrasonic at 50 times for 30 seconds. Finally the GCE was cleaned with distilled water and dried with nitrogen for use.

\section{3) Preparation of fumarate reductase/PEI-RGO/GCE}

$10 \mu \mathrm{L}$ PEI-RGO composite was added to the surface of the cleaned GCE. After drying at room temperature, $5 \mu \mathrm{L}$ fumarate reductase was added and stored at $4^{\circ} \mathrm{C}$. Before the electrical test, $5 \mu \mathrm{L} 0.05 \%$ naphthol was added GCE to prevent the enzyme from leaking [11]-[15].

\section{4) Electronic test}

In this work, electrical testing methods is mainly cyclic voltammetry (CV). The electrode working system is composed of a modified glassy carbon electrode (GCE), a platinum wire electrode (Pt) as a counter electrode, and a saturated calomel electrode (SCE) as a reference electrode. The range of potential scanning $1 \mathrm{~V}-1 \mathrm{~V}$ and all electrical tests were carried out at room temperature. What's more, all electrical tests were performed in $10.0 \mathrm{~mL} 0.1 \mathrm{M} \mathrm{pH} 7.4$ and anaerobic PBS buffer. Before these tests, high purity nitrogen was passed to the buffer for about 30 minutes to remove the dissolved oxygen [16].

The electrical-driven fumaric acid metabolism was performed $20 \mu \mathrm{L} 1 \mathrm{M}$ umaric acid was injected into $10.0 \mathrm{~mL}$ 
0.1 M pH 7.4 and anaerobic PBS buffer. The metabolic profile of fumarate and cyclic voltammetry curves were recorded.

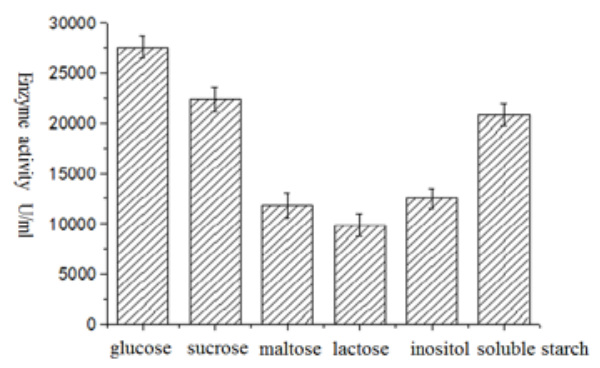

Fig. 4. The effect of carbon source on the enzyme production.

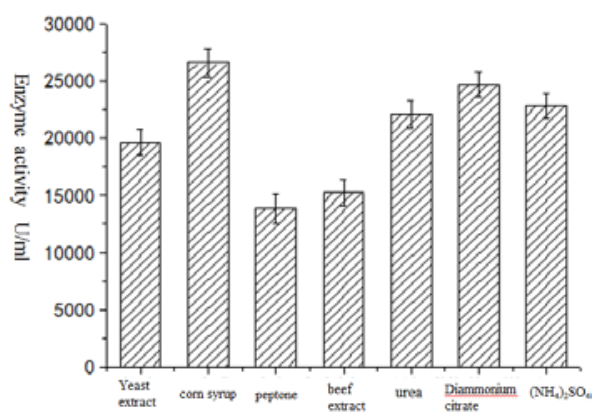

Fig. 5. The effect of nitrogen source on the enzyme production.

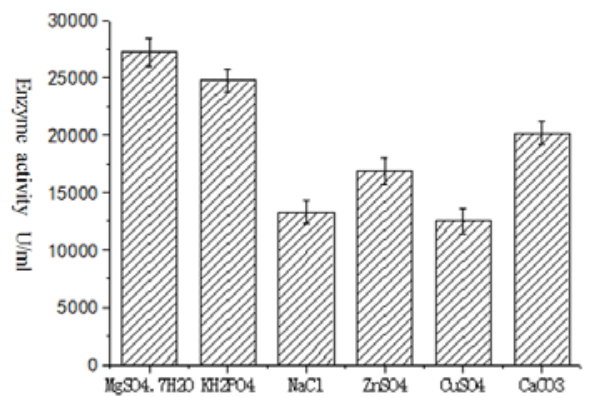

Fig. 6. The effect of inorganic salt ions on enzyme production.

\section{RESULTS AND DiSCUSSION}

\section{A. Optimization of Fermentation Medium for} Fermentation

The effect of carbon source on the enzyme production (Fig. 4): Select glucose, sucrose, soluble starch as a carbon source, the enzyme activity is higher.

The effect of nitrogen source on the enzyme production (Fig. 5): Select the organic nitrogen source of corn steep liquor and inorganic nitrogen source diammonium citrate, ammonium sulfate as the best compound nitrogen source for the production of Brevibacterium ammoniagenes.

The effect of inorganic salt ions on enzyme production (Fig. 6): Select $\mathrm{MgSO}_{4} \cdot 7 \mathrm{H}_{2} \mathrm{O}, \mathrm{KH}_{2} \mathrm{PO}_{4}, \mathrm{CaCO}_{3}$ as inorganic salt ions source, the enzyme activity is higher.

The Plackett-Burman experiment design result in Table I. Table II is analyzed using Design-Expert software. The results are shown in Table II.

Thus, three factors (maize pulp, glucose, $\mathrm{MgSO}_{4} \cdot 7 \mathrm{H}_{2} \mathrm{O}$ ) has greatest impact on enzyme activity.
TABLE I: PLACKETT-BURMAN EXPERIMENT DESIGN

\begin{tabular}{cccccccccccccc}
\hline \multicolumn{1}{c}{ Std } & Run & & \multicolumn{1}{c}{ variable } & & & & & & \\
& & A & B & C & D & E & F & G & H & I & J & K & activity \\
& & & & & & & & & & & & & \\
\hline 1 & 6 & 1 & 1 & -1 & 1 & 1 & -1 & -1 & -1 & -1 & 1 & -1 & 23357 \\
2 & 10 & -1 & 1 & 1 & -1 & 1 & 1 & 1 & -1 & -1 & -1 & 1 & 19265 \\
3 & 4 & 1 & -1 & 1 & 1 & -1 & 1 & 1 & 1 & -1 & -1 & -1 & 26923 \\
4 & 12 & -1 & 1 & -1 & 1 & 1 & -1 & 1 & 1 & 1 & -1 & -1 & 23287 \\
5 & 1 & -1 & -1 & 1 & -1 & 1 & 1 & -1 & 1 & 1 & 1 & -1 & 21393 \\
6 & 7 & -1 & -1 & -1 & 1 & -1 & 1 & 1 & -1 & 1 & 1 & 1 & 23979 \\
7 & 2 & 1 & -1 & -1 & -1 & 1 & -1 & 1 & 1 & -1 & 1 & 1 & 23386 \\
8 & 5 & 1 & 1 & -1 & -1 & -1 & 1 & -1 & 1 & 1 & -1 & 1 & 23328 \\
9 & 3 & 1 & 1 & 1 & -1 & -1 & -1 & 1 & -1 & 1 & 1 & -1 & 20393 \\
10 & 11 & -1 & 1 & 1 & 1 & -1 & -1 & -1 & 1 & -1 & 1 & 1 & 24252 \\
11 & 8 & 1 & -1 & 1 & 1 & 1 & -1 & -1 & -1 & 1 & -1 & 1 & 21743 \\
12 & 9 & -1 & -1 & -1 & -1 & -1 & -1 & -1 & -1 & -1 & -1 & -1 & 17816 \\
\hline
\end{tabular}

TABLE II: VARIANCE ANALYSIS OF PLACKETT-BURMAN

\begin{tabular}{cccc}
\hline $\begin{array}{c}\text { Source of } \\
\text { variance }\end{array}$ & F Text & Prob $>$ F & significance \\
\hline glucose & 758.93 & 0.0231 & 3 \\
sucrose & 9.93 & 0.1957 & 8 \\
Soluble starch & 14.39 & 0.1641 & 7 \\
corn syrup & 2875.49 & 0.0119 & 1 \\
Ammonium & 128.65 & 0.0560 & 6 \\
sulfate & & & 4 \\
Diammonium & 473.13 & 0.0292 & 5 \\
citrate & & & 2 \\
$\mathrm{KH}_{2} \mathrm{PO}_{4}$ & 242.14 & 0.0409 & 9 \\
$\mathrm{MgSO}_{4} \cdot 7 \mathrm{H}_{2} \mathrm{O}$ & 2297.49 & 0.0133 & \\
$\mathrm{CaCO}_{3}$ & $1.410 \times 10^{-3}$ & 0.9708 & \\
\hline
\end{tabular}

\section{B. Enzymatic Ammonium Sulfate Fractionation Salt Precipitation}

The supernatant was ultrasonic treatment by ammonium sulphate with different saturation, and the supernatant enzyme activity was detected. The results are shown in Table III and Fig. 7.

Fig. 7 showed that fumarate reductase begins to when ammonium sulfate saturation level is greater than $15 \%$. When ammonium sulfate saturation level was $65 \%$, all fumarate reductase precipitated out. Therefore, the first step is to remove the contaminating protein with ammonium sulphate at a saturation of $0 \%$ to $15 \%$. After centrifugation, ammonium sulfate was added to the supernatant to reach to a saturation of $65 \%$, the fumarate reductase protein precipitate.

TABLE III: THE RESUlT OF AMMONIUM SULFATE FRACTION PRECIPITATION

$\begin{array}{lccccccc}\begin{array}{l}\text { Different saturation } \\ \text { of }\left(\mathrm{NH}_{4}\right)_{2} \mathrm{SO}_{4}(\%)\end{array} & 0 & 15 & 25 & 35 & 45 & 55 & 65 \\ & 10 & & & & & & \\ \text { Enzyme activity(\%) } & 0 & 94.6 & 86.8 & 52.7 & 36.7 & 12.9 & 0\end{array}$




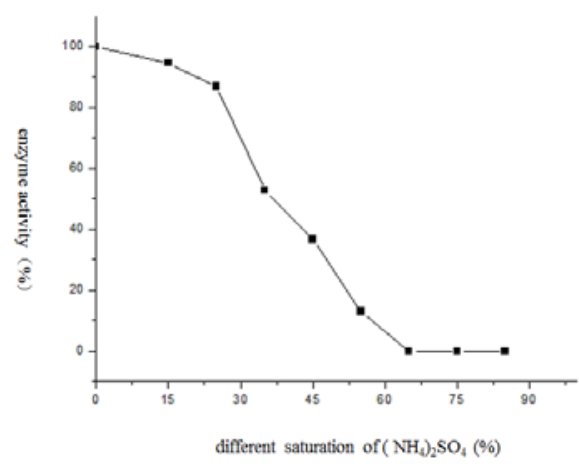

Fig. 7. The relationship between different saturation of $\left(\mathrm{NH}_{4}\right)_{2} \mathrm{SO}_{4}$ and enzyme activity.

\section{Preliminary Results of Enzyme Purification}

Through ultrasonic separation, gel chromatography and $65 \%$ ammonium sulfate fractionation, the fumarate reductase specific activity reached to $106 \mathrm{U} / \mathrm{mg}$, the purification ratio was 12.8 times and the recovery was $24 \%$ in Table IV.

TABLE IV: THE PURIFICATION PRODURES OF THE FUMARASE REDUCTASE

\begin{tabular}{cccccc}
\hline project & $\begin{array}{c}\text { all enemy } \\
\text { activity } \\
(\mathrm{U})\end{array}$ & $\begin{array}{c}\text { all } \\
\text { protein } \\
(\mathrm{mg})\end{array}$ & $\begin{array}{c}\text { specific } \\
\text { activity } \\
(\mathrm{U} / \mathrm{mg})\end{array}$ & $\begin{array}{c}\text { purificati } \\
\text { on ratio }\end{array}$ & $\begin{array}{c}\text { recover } \\
\text { y ratio } \\
(\%)\end{array}$ \\
\hline $\begin{array}{c}\text { ultrasonic } \\
\text { separation } \\
65 \%\end{array}$ & 27210 & 3309 & 8.24 & 1 & 100 \\
$\begin{array}{c}\text { ammonium } \\
\text { sulfate }\end{array}$ & 15640 & 213 & 73.22 & 8.8 & 57 \\
$\begin{array}{c}\text { fractionation } \\
\text { gel }\end{array}$ & & & & & \\
chromatograp & 6499 & 61 & & & \\
hy & & & & & \\
\hline
\end{tabular}

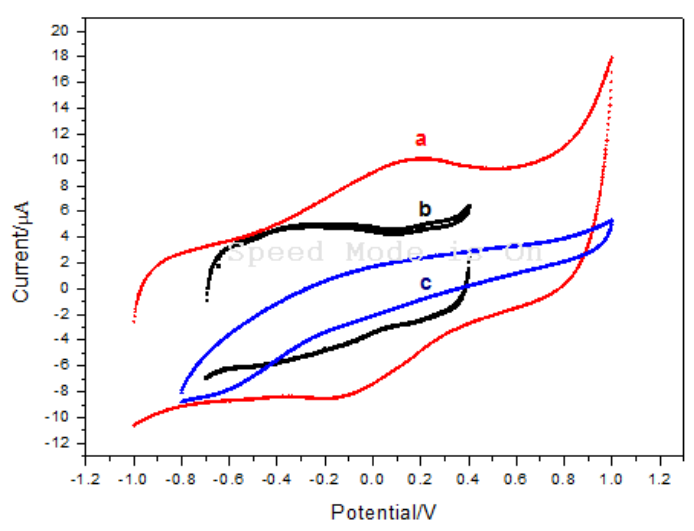

Fig. 8. (a) Fumarate reductase/PEI-RGO/GCE; (b) PEI-RGO/GCE; (c) GCE in $0.1 \mathrm{M} \mathrm{pH} 7.4$ and anaerobic PBS buffer at $100 \mathrm{mV} \cdot \mathrm{S}^{-1}$.

\section{Direct Electrical Study of Fumarate Reductase/PEI- $R G O / G C E$}

Fig. 8 and Fig. 9 show the cyclic voltammetric curves of GCE, PEI-RGO/GCE and fumarate reductase/PEI-RGO/GCE in $10.0 \mathrm{~mL} 0.1 \mathrm{M} \mathrm{pH} 7.4$ and anaerobic PBS buffer (scan rate at $100 \mathrm{mv} / \mathrm{s}$ ). The curve (a) of fumarate reductase/PEI-RGO/GCE had a pair of obvious redox peaks with peak potentials of $-0.166 \mathrm{~V}$ and $0.179 \mathrm{~V}$, respectively. The corresponding peak currents were $-8.582 \mu \mathrm{A}$ and $9.966 \mu \mathrm{A}$. While the curve (c) and curve (b) had no redox peaks. Thus, it is indicated that fumarate reductase was capable of directing electron transfer rapidly and stably on the PEI-RGO /GCE surface, which was caused by fumarase reductase immobilized on the GCE. On the other hand, it is proved that fumarase reductase was successfully fixed on the GCE.

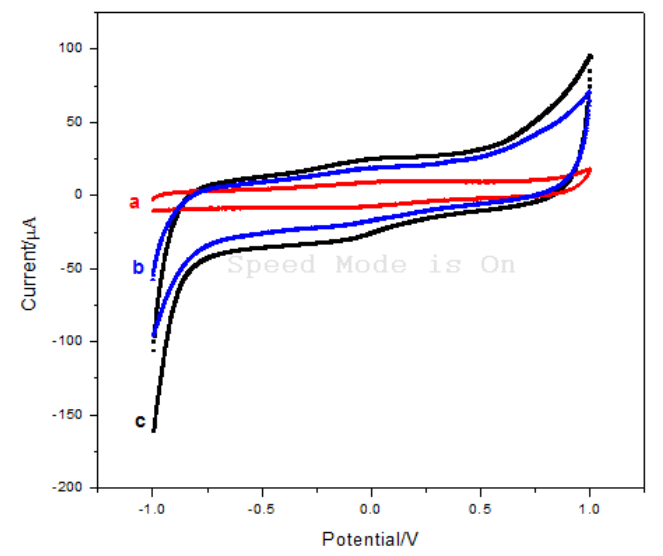

Fig. 9. Fumarate reductase/PEI-RGO/GCE in anaerobic (a); air saturation (b); air saturated with $0.1 \mathrm{M} \mathrm{pH=7.4} \mathrm{PBS}$ buffer (C).

\section{E. The Electronical Catalytic Behavior of Fumarate Reductase/PEI-RGO/GCE to Fumaric Acid}

The electronical catalytic behavior of Fumarate reductase/PEI-RGO/GCE to fumaric acid is shown in Fig. 10. When dissolved oxygen is present, like curve (b), the cyclic voltammetric curves of direct electronical transfer of fumarate reductase/PEI-RGO/GCE changed and the reduction current significantly increased. By adding $100 \mu \mathrm{M}$ fumaric acid to the PBS buffer, the cyclic voltammetric curves of fumarate reductase/PEI-RGO/GCE also showed a significant change and the reduction peak current continued to increase. As there was only one pair of redox peak in the whole scanning range, and the peak potential coincided with the peak potential of the fumarate reductase/PEI-RGO/GCE under anaerobic conditions, indicated that the fumarate reductase immobilized on the electrode not only maintained a certain activity, but also can catalyze the metabolism of fumaric acid effectively.

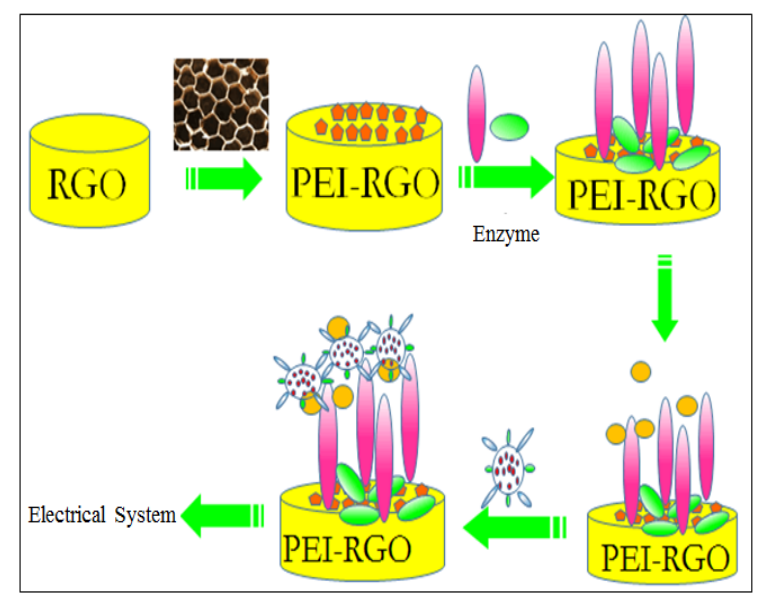

Fig. 10. System of fumarate reductase/PEI-RGO/GCE. 


\section{CONCLUSION}

Through ultrasonic separation, gel chromatography and $65 \%$ ammonium sulfate fractionation, the fumarate reductase specific activity reached to $106 \mathrm{U} / \mathrm{mg}$, the purification ratio was 12.8 times and the recovery was $24 \%$

Combined with good biocompatibility, excellent electrical conductivity and large surface area of graphene and the advantages of polyethyleneimine with excellent water solubility, excellent model ability, rich functional groups and other characteristics, the polyethyleneimine reductive graphene composites (PEI-RGO) showed good performance.Fumarate reductase was immobilized on the surface of PEI-RGO modified electrode by electrostatic adsorption. The GCE was used to replace the coenzyme $\mathrm{NADH}$ to provide electrons for the metabolism of fumarate reductase in vitro. At last, the curve of fumarate reductase/PEI-RGO/GCE had a pair of obvious redox peaks with peak potentials of $-0.166 \mathrm{~V}$ and $0.179 \mathrm{~V}$, respectively. The corresponding peak currents were $-8.582 \mu \mathrm{A}$ and $9.966 \mu \mathrm{A}$. The results show that through the electronical system, fumarate reductase can not only to achieve the electronic transmission between the electrodes, but also advance the accumulate metabolism of fumaric acid. This work provides a solid theoretical basis for fumarate reductase to product succinic acid in vitro.

\section{ACKNOWLEDGMENT}

This research work was financially supported by the state key development program of China (2016YED0201002). We thank the editor and the anonymous reviewers.

\section{REFERENCE}

[1] J. G. Zeikus, M. K. Jain, and P. Elankovan, "Biotechnology of succinic acid production and markets for derived industrial products," App Microbiol Biot, vol. 51, no. 5, pp. 545-552, 1999.

[2] G. Fuchs, E. Stupperich, and R. K. Thauer, "Function of fumarate reductase in methanogenic bacteria (Methanobacterium)," Arch Microbiol, vol. 119, no. 2, pp. 215-218, 1978.

[3] J. B. Mckinlay, C. Vieille, and J. G. Zeikus, "Prospects for a bio-based succinate industry,” App Microbiol Biot, vol. 76, no. 4, pp. 727-740, 2007.

[4] C. Dongmei, L. Mi, X. Xu, L. Jusheng, Q. Jing, and L. Songqin, "Nanocomposites of graphene and cytochrome P450 2D6 isozyme for electrochemical-driven tramadol metabolism,” Langmuir, vol. 30, no. 39, pp. 11833-11840, 2014.

[5] B. Derkus, E. Emregul, C. Yucesan, and K. C. Emregul, "Myelin basic protein immunosensor for multiple sclerosis detection based upon label-free electrochemical impedance spectroscopy,” Biosens Bioelectron, vol. 46, no.16, pp. 53-60, 2013.

[6] R. R. Gokarn, M. A. Eiteman, and E. Altman, "Expression of pyruvate carboxylase enhances succinate production inEscherichia coli without affecting glucose uptake,” Biotechnol Lett, vol. 20, no.8, pp. 795-798, 1998.

[7] G. A. Hebert, P. L. Pelham, and B. Pittman, "Determination of the optimal ammonium sulfate concentration for the fractionation of rabbit, sheep, horse, and goat antisera," J. Gen. Appl. Microbiol, vol. 25, no. 1, pp. 26-36, 1973.

[8] Y. Yuan, X. Gou, R. Yuan, Y. Chai, Y. Zhuo, X. Ye, and X. Gan, "Graphene-promoted 3， 4, 9, 10-perylenetetracarboxylic acid nanocomposite as redox probe in label-free electrochemical aptasensor," Biosens Bioelectron, vol. 30, no. 1, pp. 123-127, 2011.

[9] M. J. Fernandez-Merino, L. Guardia, J. I. Paredes, S. Villar-Rodil, P. Solis-Fernandez, A. Martinez-Alonso, and J. M. D. Tascon, "Vitamin C is an ideal substitute for hydrazine in the reduction of graphene oxide suspensions," J. Phys. Chem. C., vol. 114, no. 14, pp. 6426-6432, 2010.

[10] M. Huang, X. Xu, H. Yang, and S. Liu, "Electrochemically-driven and dynamic enhancement of drug metabolism via cytochrome P450 microsomes on colloidal gold/graphene nanocomposites,” Rsc. Advances, vol. 2, no. 33, pp. 12844-12850, 2012.

[11] J. Lu, W. Wei, L. Yin, Y. Pu, and S. Liu, "Flow injection chemiluminescence immunoassay of microcystin-LR by using PEI-modified magnetic beads as capturer and HRP-functionalized silica nanoparticles as signal amplifier,” The Analyst, vol. 138, no. 5, pp. 1483-1489, 2013.

[12] T. G. Park, J. H. Jeong, and S. W. Kim, "Current status of polymeric gene delivery systems,” Adv. Drug Deliver Rev., vol. 58, no. 4, pp. 467-86, 2006.

[13] B. Willner, E. Katz, and I. Willner, "Electrical contacting of redox proteins by nanotechnological means," Curr. Opin. Biotechnol, vol. 17, no. 6, pp. 589-596, 2006.

[14] Q. Xue, D. Kato, T. Kamata, Q. Guo, T. You, and O. Niwa, "Human cytochrome P450 3A4 and a carbon nanofiber modified film electrode as a platform for the simple evaluation of drug metabolism and inhibition reactions," Analyst, vol. 138, no. 21, pp. 6463-6468, 2013.

[15] S. Wen, F. Zheng, M. Shen, and X. Shi, "Surface modification and PEGylation of branched polyethyleneimine for improved biocompatibility," J. Appl. Polym. Sci., vol. 128, no. 6, pp. 3807-3813, 2013.

[16] M. Sheng, Y. Gao, J. Sun, and F. Gao, "Carbon nanodots-chitosan composite film: a platform for protein immobilization, direct electrochemistry and bioelectrocatalysis," Biosens Bioelectron, vol. 58, no. 8, pp. 351-358, 2014.

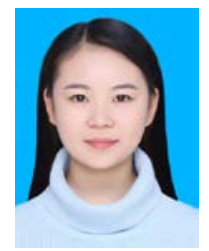

Yemin Yu comes from Nanjing, Jiangsu Province, China. Now study in Nanjing Tech University, master's degree in second grade.

She does research as a postgraduate student in Huyonghong laboratory and has published two papers in important journal.

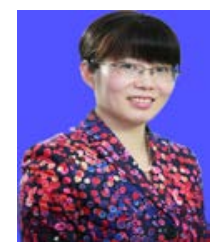

Yonghong Hu is with College of Biotechnology and Pharmaceutical Engineering, State Key Laboratory of Materials-Oriented Chemical Engineering, Nanjing Tech University, Nanjing 211816, China.

In the last five years, she has taken in hand more than 30 Provincial and ministerial level projects included 867, 973, National Natural Science Foundation of China, transformation of achievements. She won the prize of national and provincial science and technology about 11 and the prize of the provincial teaching 12 . In the past three years, more than 70 papers were published in important journals at home and abroad, and 59 articles were included in SCI. She applied for 36 national invention patents, and 17 patents were authorized. She has published 10 books. 